There is no doubt that after the war there was a great increase of venereal disease, which is reflected in the number of cases of ophthalmia neonatorum which occurred.

The venereal clinics and the better education of the public with regard to preventive measures have apparently caused some decrease in their numbers. At the same time we must keep in mind that all cases of ophthalmia neonatorum are not due to the gonococcus, and that the 60 per cent., given in most statistics, holds good for the cases admitted to St. Margaret's Hospital.

When St. Margaret's Hospital was first opened the accommodation provided was barely sufficient to cope with the number of cases admitted, but the addition of two large open-air balconies for the accommodation of the infants who are admitted in a poor state of health without the mothers, added 24 more cots to the Institute with the result that there are now available 40 cots and 16 beds. Since these additional beds have been added, the hospital has never been worked at its full capacity, although according to the notifications there are more than a sufficient number of cases to fill it.

There are a number of reasons for this.

First, this Institution is still by no means known to the whole of the medical profession; secondly, a number of the cases notified are of the very mildest type and do not require institutional treatment; thirdly, cases are no doubt in some instances efficiently treated at home; fourthly, some hospitals still undertake the treatment of the cases as out-patients ; and, fifthly, it has been said that this hospital is liable to become known as an institution for venereal disease. With regard to the last criticism, although some mothers must necessarily know the nature of the disease from which they are suffering, strict precautions are taken against their informing other patients who are admitted to the hospital. No doubt it would be better that the name of the disease should be masked by calling the institutions "Infant Welfare Centres" rather than hospitals for ophthalmia neonatorum.

\title{
The State Recognition of Opticians
}

If any confirmation of the wisdom of the recent recommendation of the Council of British Ophthalmologists on the question of the official recognition of opticians were required it is supplied by a case reported from Queensland where a scheme of this nature is in operation. The case is published by Dr. J. Lockhart Gibson, of Brisbane, in the Medical Journal of Australia for January 14, 1922. The patient was a girl of eight. Shortly before she came under Dr. Lockhart's care her parents had been advised to take 
her to see an oculist as the right eye was blind. The mother, instead, took her to an optician. The optician, after examining the eyes, was asked by the mother whether she ought to take the child to a doctor. "Quite unnecessary," he said, "we see many such cases." Fortunately, in this particular case, the mother was not satisfied and brought the child to see Dr. Lockhart, who found an advanced glioma of the retina. In commenting on the case Lockha:t says, "we cannot, of course, blame the optician for not knowing that the eye was in a serious state and a danger to the child, because an optician, however expert in the grinding of lenses and preparation of spectacles, could not possibly have any opinion of value on the real state of an eye. Prior to the registration of opticians as sight-testers, the blame would have rested on the parents of the child, had they been satisfied with the optician's opinion. It is impossible to avoid the belief that the blame now would have rested on the Government which registered him. . . . Opticians in Queensland have been placed in a false position. Were chemists to be registered to prescribe medicines, they would be placed in an exactly parallel position and one which the whole profession would understand." This certainly does not over-state the case. Such a case as this is doubtless a very glaring example and one in which life itself was involved, but cases in which such conditions as glaucoma would not be recognized at the period when treatment is likely to be successful would be only too common. It is to be hoped that no British Government will be so foolish as to give way on a question so vitally affecting the interests of the nation.

\section{ABSTRACTS \\ I.-TUBEROSE SCLEROSIS WITH EYE COMPLICATIONS}

van der Hoeve, J. (Leyden).-Ocular new-growths in tuberose sclerosis of the brain. [Augengeschwiulste bei der tuberöse, Hirnsclerose (Bournville.)] Arch.f. Ophthal., Vol. CV.

van der Hoeve examined the eyes of a girl, 17 years of age, suffering from tuberose sclerosis of the brain, a disease described by Bournville in 1880 .

He observed multiple, flat, scarcely raised new-growths in the retina, some of which showed concretions on their surface, and a growing tumour of the optic disc.

The changes in the latter were followed from day to day-cysts 